\title{
Mixture of fuels approach for the solution combustion synthesis of $\mathrm{Al}_{2} \mathrm{O}_{3}-\mathrm{ZrO}_{2}$ nanocomposite
}

\author{
S.T. Aruna*, K.S. Rajam \\ Surface Engineering Division, National Aerospace Laboratories, Post Bag No. 1779, Bangalore 560 017, India
}

Received 28 March 2003; received in revised form 8 October 2003; accepted 19 October 2003

\begin{abstract}
A modified solution combustion approach was used for the first time in the preparation of nanosize zirconia toughened alumina (ZTA) composite. ZTA-1 with an average particle size of $\sim 37 \mathrm{~nm}$ was prepared using corresponding metal nitrates and urea. ZTA- 2 with an average particle size of $<10 \mathrm{~nm}$ was prepared by using mixture of fuels such as ammonium acetate, urea and glycine. The products formed were characterised by powder X-ray diffractometry, Transmission electron microscopy and BET surface area analysis. By using mixture of fuels, the energetics of the combustion reaction and eventually the properties of the combustion product have been changed. A series of combustion reactions were carried out to optimise the fuel ratio combinations required to obtain $<10 \mathrm{~nm}$ ZTA particles. The microstructure of ZTA consisted of crystallites of $\mathrm{Al}_{2} \mathrm{O}_{3}$ and $\mathrm{ZrO}_{2}$ both of which were nanocrystalline as evident from TEM.
\end{abstract}

(C) 2003 Elsevier Ltd. All rights reserved.

Keywords: A. Nanostructure; A. Composite; C. Electron microscopy; C. X-ray diffraction.

\section{Introduction}

Synthesis of advanced ceramics and other specialty materials as nanoparticles is one of the major challenges in material processing technology [1-3]. The specific advantages of nanocrystalline materials are superior phase homogeneity, enhanced sinterability at a relatively low temperature, and microstructure leading to unique mechanical, electrical, dielectric, magnetic and optical properties [3]. Using a conventional solid-state route, it is not possible to obtain nanosized powders because the initial sizes of the reactants themselves are much larger.

Tetragonal zirconia in an alumina matrix is known as zirconia toughened alumina (ZTA). ZTA is a high purity combination of the low cost of alumina and high strength of zirconia. ZTA is a ceramicceramic composite with good mechanical properties [4]. The enhanced strength and toughness have

\footnotetext{
* Corresponding author. Tel.: +91-080-5086250; fax: +91-080-5210113.

E-mail address: aruna_reddy@css.cmmacs.ernet.in (S.T. Aruna).
} 
made the ZTAs more widely applicable and more productive than plain ceramics and cermets in machining steels and cast irons [5]. ZTA ceramics are attractive materials due to the combination of both $\mathrm{ZrO}_{2}$ and $\mathrm{Al}_{2} \mathrm{O}_{3}$ properties. ZTA shows a considerable improvement in strength and more importantly toughness. It is three to four times more abrasion resistant than high purity alumina. ZTA exhibits a fracture toughness of $7 \mathrm{MPa} \mathrm{m}^{1 / 2}$, hardness of $15 \mathrm{GPa}$ and flexural strength of $910 \mathrm{MPa}$ [6]. As a result, these ceramics can be used in areas of extreme mechanical abrasion and thermal shock. It is used in cutting tools and nozzles for spraying of abrasives. The synthesis of nanomaterials has become an area of interest in recent years. Several methods of preparing ZTA composites have been reported in the literature like conventional dry milling [7] or wet milling [8] of the mixture of zirconia and alumina, sol-gel [9], liquid precursor methods [10], etc. However, all these techniques are quite involved and need high temperatures and long processing times.

Solution combustion technique is a versatile process leading to syntheses of single phase, solid solutions, composites as well as complex compound oxide phases in homogeneous form. This process has the advantage of choice of a wide variety of fuels, rapid cooling leading to nucleation of crystallites without any growth and also has the potential to scale up [11]. Because of the gas evolution, large particles or agglomerates can be disintegrated during the process and the products formed are of high purity. The resulting product is very fine particulates of friable agglomerates that can be easily ground to obtain a much finer particle size.

In most of the processes, during the preparation of $\mathrm{ZTA}, \mathrm{Al}_{2} \mathrm{O}_{3}$ will be formed as a metastable $\gamma$-phase. In case of ZTA prepared by solution combustion process using urea as fuel, $\alpha$-alumina has been formed, which is beneficial to the consolidation process [12]. The main theme of this paper is to explore the various fuel mixture combinations required for the preparation of nanosize ZTA by solution combustion technique.

Urea has been proven to be a better fuel for the preparation of alumina and alumina related compounds and glycine for zirconia and zirconia related compounds by solution combustion technique $[13,14]$. Hence, the objective of the present study is to prepare ZTA $\left((1-x) \mathrm{Al}_{2} \mathrm{O}_{3}-x \mathrm{ZrO}_{2} ;(x=0.2)\right)$ nanocomposite by solution combustion route by employing mixture of fuels. The current work is in a niche of area of research in the sense that, to the best of our knowledge, there are no reports on the use of mixture of fuels (using commercially available chemicals) concept for the preparation of composites by solution combustion route.

\section{Experimental}

The starting chemicals used in this study were $\mathrm{Al}\left(\mathrm{NO}_{3}\right)_{3} \cdot 9 \mathrm{H}_{2} \mathrm{O}$ (Merck), $\mathrm{Zr}\left(\mathrm{NO}_{3}\right)_{4}$ (Hi-tech trade), Urea $(\mathrm{BDH})$, Ammonium acetate $(\mathrm{BDH})$, Ammonium nitrate (Sarabhai) and Glycine (BDH).

An attempt was first made to reduce the exothermicity of the combustion reaction involving the preparation of alumina by solution combustion technique so as to reduce the particle size. The following set of experiments were carried out.

\subsection{Preparation of $\mathrm{Al}_{2} \mathrm{O}_{3}$}

As reported in the literature, $\alpha$-alumina $\left(\mathrm{Al}_{2} \mathrm{O}_{3}-1\right)$ was prepared by heating rapidly an aqueous redox mixture containing stoichiometric amounts of aluminium nitrate $(20 \mathrm{~g})$ and urea $(8 \mathrm{~g})$ on a preheated 
Table 1

Properties of alumina prepared by solution combustion process using various fuel compositions

\begin{tabular}{llll}
\hline Sample name & Fuel composition & Particle size (from XRD) & Agglomerate size \\
\hline $\mathrm{Al}_{2} \mathrm{O}_{3}-1$ & $\mathrm{U}$ & $50 \mathrm{~nm}$ & $10 \mu \mathrm{m}$ \\
$\mathrm{Al}_{2} \mathrm{O}_{3}-2$ & $0.5 \mathrm{U}+0.5 \mathrm{AA}$ & Poorly crystalline & - \\
$\mathrm{Al}_{2} \mathrm{O}_{3}-3$ & $0.6 \mathrm{U}+0.4 \mathrm{AA}$ & Poorly crystalline & - \\
$\mathrm{Al}_{2} \mathrm{O}_{3}-4$ & $0.75 \mathrm{U}+0.25 \mathrm{AA}$ & $30 \mathrm{~nm}$ & $5.6 \mu \mathrm{m}$ \\
\hline
\end{tabular}

$\mathrm{U}$ : urea.AA: ammonium acetate.

hotplate $\left(\sim 400{ }^{\circ} \mathrm{C}\right)$. The solution containing the above redox mixture boils, foams, catches fire and burns with an incandescent flame to yield $\mathrm{Al}_{2} \mathrm{O}_{3}$ with the evolution of large amounts of gases as reported in the literature [13]. A stoichiometric composition is defined as the composition where ratio of oxidising valency to reducing valency is equal to unity and ensures that the evolution of heat is maximised. The total oxidising and reducing valencies of the reactants were determined as proposed by Jain et al. [15].

Similarly $\mathrm{Al}_{2} \mathrm{O}_{3}-2, \mathrm{Al}_{2} \mathrm{O}_{3}-3$ and $\mathrm{Al}_{2} \mathrm{O}_{3}-4$ were prepared using various ratios of urea and ammonium acetate as illustrated in Table 1. It has been shown that urea when used as a fuel leads to a flaming type combustion and in the course of this, if the flame persists for a longer duration, then the particles have enough time and temperature to sinter and thus yielding larger particles [16]. So in order to prevent the sinterability and reduce the exothermicity, the urea amount was decreased. For example, in the preparation of $\mathrm{Al}_{2} \mathrm{O}_{3}-4$, the stoichiometric amount of urea (U) calculated was not used instead, 0.75 times the stoichiometric ratio $(0.75 \mathrm{U})$ was used, i.e. instead of $8 \mathrm{~g}$ urea, $6 \mathrm{~g}$ urea was used (for $20 \mathrm{~g}$ of aluminium nitrate). To compensate the fuel ratio, an extra fuel ammonium acetate (AA) was used. Similarly, instead of $5.59 \mathrm{~g}$ of ammonium acetate, $1.4 \mathrm{~g}(0.25$ times the stoichiometric value (0.25AA)) was used. Similar experiments were carried out with the following fuel compositions: $0.6 \mathrm{U}+0.4 \mathrm{AA}$, $0.5 \mathrm{U}+0.5 \mathrm{AA}, 0.7 \mathrm{U}+0.3 \mathrm{AA}$ to prepare $\alpha-\mathrm{Al}_{2} \mathrm{O}_{3}$. The reaction was smouldering type with $0.5 \mathrm{U}+0.5 \mathrm{AA}$ and $0.6 \mathrm{U}+0.4 \mathrm{AA}$ fuel compositions. However, the combustion reaction with $0.75 \mathrm{U}+0.25 \mathrm{AA}$ fuel composition was flaming and there was more frothing. The combustion reaction almost becomes smouldering type with increasing ammonium acetate and decreasing urea amount.

\subsection{Preparation of ZTA}

A nominal composition of $\mathrm{Al}_{2} \mathrm{O}_{3}$ with 20 wt.\% addition of $\mathrm{ZrO}_{2}\left((1-x) \mathrm{Al}_{2} \mathrm{O}_{3}-x \mathrm{ZrO}_{2} ;(x=0.2)\right)$ (ZTA) was synthesised by solution combustion technique. No stabiliser like $\mathrm{Y}_{2} \mathrm{O}_{3}$ was used to stabilise zirconia. ZTA was prepared using both urea and a mixture of fuels. The total oxidising and reducing valencies of the reactants were adjusted by determining the equivalence ratio as unity [15]. ZTA-1 was prepared by rapidly heating an aqueous redox mixture containing stoichiometric amounts of aluminium nitrate, zirconium nitrate and urea (fuel). ZTA-2 was prepared using mixture of fuels as follows: $0.75 \mathrm{U}+0.25 \mathrm{AA}$ corresponding to the weight of $\mathrm{Al}_{2} \mathrm{O}_{3}$ and stoichiometric amount of glycine corresponding to the $\mathrm{ZrO}_{2}$ weight. Glycine fuel facilitates smooth combustion with zirconium nitrate and hence glycine was used. Usually, glycine fuel ends up in combustion products with traces of carbon. So ammonium nitrate which acts as an extra oxidiser was used along with glycine. Ammonium nitrate is not in itself combustible but, as it is an oxidising agent, it can assist other materials to burn, even if air is excluded [17]. The combustion reaction of ZTA-1 with urea was highly flaming while that of ZTA-2 prepared using mixture of fuels was like the burning of a cigarette. 
The theoretical stoichiometric equations for the formation of ZTA-1 (Eq. (1)) and ZTA-2 (Eq. (2)) can be written as follows:

$$
\begin{aligned}
& 8 \mathrm{Al}\left(\mathrm{NO}_{3}\right)_{3}+\mathrm{Zr}\left(\mathrm{NO}_{3}\right)_{4}+24 \mathrm{CH}_{4} \mathrm{~N}_{2} \mathrm{O}+\frac{1}{2} \mathrm{O}_{2} \\
& \quad \rightarrow\left(4 \mathrm{Al}_{2} \mathrm{O}_{3}\right)-\mathrm{ZrO}_{2}+24 \mathrm{CO}_{2}+47 \mathrm{H}_{2} \mathrm{O}+38 \mathrm{~N}_{2} \\
& \quad 8 \mathrm{Al}\left(\mathrm{NO}_{3}\right)_{3}+\mathrm{Zr}\left(\mathrm{NO}_{3}\right)_{4}+15 \mathrm{CH}_{4} \mathrm{~N}_{2} \mathrm{O}+3 \mathrm{NH}_{4} \mathrm{NO}_{3}+\mathrm{CH}_{3} \mathrm{COONH}_{4}+5 \mathrm{C}_{2} \mathrm{H}_{5} \mathrm{O}_{2} \mathrm{~N}+\frac{7}{2} \mathrm{O}_{2} \\
& \quad \rightarrow\left(4 \mathrm{Al}_{2} \mathrm{O}_{3}\right)-\mathrm{ZrO}_{2}+27 \mathrm{CO}_{2}+52 \mathrm{H}_{2} \mathrm{O}+32 \frac{1}{2} \mathrm{~N}_{2}+2 \frac{1}{2} \mathrm{NO}_{2}
\end{aligned}
$$

The crystallinity and phase identification of the powders was determined by using Philips X-ray diffractometer with $\mathrm{Cu} \mathrm{K} \alpha$ as the radiation source and $\mathrm{Ni}$ as the filter. The average crystallite size was obtained by the line-broadening method. The full width at half maximum (FWHM) of the peak corresponding to ( $\left(\begin{array}{lll}1 & 1 & 1\end{array}\right)$ reflection of the tetragonal zirconia and the peak corresponding to (llll 04 of $\alpha$ $\mathrm{Al}_{2} \mathrm{O}_{3}$ was measured and the average crystallite size values were estimated using the following equation of Scherrer and Warren:

$$
D=\frac{0.9 \lambda}{\left(B^{2}-b^{2}\right)^{1 / 2} \operatorname{Cos} \theta}
$$

where $D$ is the crystallite size, $\lambda$ the wavelength of the radiation, $\theta$ the Bragg's angle and $B$ and $b$ are the FWHMs observed for the sample and standard, respectively. Silicon powder with a mean particle diameter of $25 \mu \mathrm{m}$ was used to measure the instrumental peak broadening.

A JEOL-JEM 100SX Transmission electron microscope, operating at $120 \mathrm{kV}$ was used to determine the shape and size of the particles. For TEM, the powders were crushed and ultrasonicated in $100 \%$ ethanol for about $10 \mathrm{~min}$. The as-dispersed powders were picked off on formvar coated $\mathrm{Cu}$ grids (300 mesh) which were subsequently carbon coated. The surface area of the powders were measured using multipoint BET method (model 2100E Accusorb, Micromeritics instrument) assuming a cross sectional area of $0.16 \mathrm{~nm}^{2}$ for the nitrogen molecule. Powder density was measured using a pycnometer with xylene as the liquid medium. The average agglomerated particle size was measured using a photosize analyser (Sedigraph-5100).

\section{Results and discussion}

From Table 1, the following observations can be made. The particle size and also the average agglomerated particle size of $\alpha-\mathrm{Al}_{2} \mathrm{O}_{3}$ decreases with increasing amount of ammonium acetate and decreasing amount of urea. However, at lower urea concentrations $(<0.6 \mathrm{U})$ the combustion reaction changed from flaming to smouldering type. Also, as the amount of ammonium acetate was increased, the crystallite size decreased and the particles became amorphous. By carrying out several combustion reactions using different fuel ratios as illustrated in Table 1, the optimum concentration of fuel suitable for obtaining crystalline nanosize alumina with less agglomeration was found to be 0.75 urea and 0.25 ammonium acetate. Thus, for the preparation of ZTA-2, $0.75 \mathrm{U}+0.25 \mathrm{AA}$ fuel combination was used along with glycine and ammonium nitrate.

The XRD patterns of $\alpha-\mathrm{Al}_{2} \mathrm{O}_{3}-1$ and $\alpha-\mathrm{Al}_{2} \mathrm{O}_{3}-4$ are shown in Fig. 1 . The particles are crystalline and the crystallite size calculated from XRD for $\alpha-\mathrm{Al}_{2} \mathrm{O}_{3}-1$ and $\alpha-\mathrm{Al}_{2} \mathrm{O}_{3}-4$ are 50 and $30 \mathrm{~nm}$, respectively. The agglomerated particle sizes are 10 and $5.6 \mu \mathrm{m}$ for $\alpha-\mathrm{Al}_{2} \mathrm{O}_{3}-1$ and $\alpha-\mathrm{Al}_{2} \mathrm{O}_{3}-4$, respectively. Thus, by using mixture of fuels, not only the particle size was reduced but also the agglomerated particle size. X-ray 


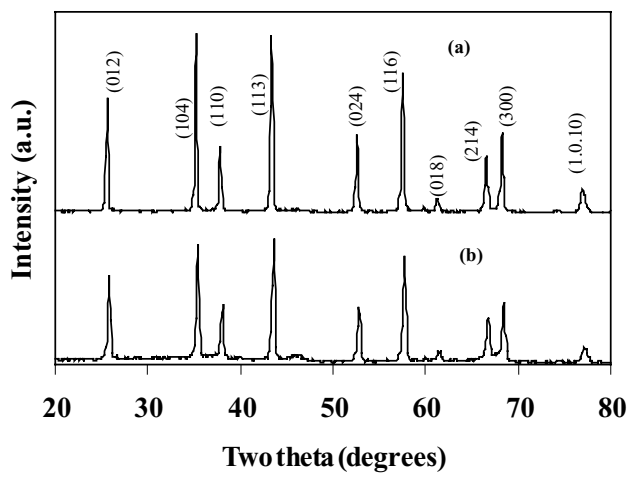

Fig. 1. Powder XRD patterns of $\alpha$-alumina: (a) using urea $(\mathrm{O} / \mathrm{F}=1)$ and $(\mathrm{b})$ using urea $(0.75)$ and ammonium acetate $(0.25)$.

diffraction pattern for the as-synthesized ZTA-1 is shown in Fig. 2. The presence of either cubic or tetragonal phases of $\mathrm{ZrO}_{2}$ is confirmed by the presence of a high intensity peak at $2 \theta=30^{\circ}$. However, peaks are split around $50^{\circ}$, exhibiting clear evidence of the presence of tetragonal structure. Also, the peaks corresponding to $\alpha-\mathrm{Al}_{2} \mathrm{O}_{3}$ are seen. The as-formed ZTA-2 powder exhibits very broad peaks confirming the nanosize nature of the powders. Due to the broad peaks observed in as-prepared ZTA-2, the $\alpha$-alumina and zirconia peaks could not be identified. So the ZTA- 2 was calcined at $900{ }^{\circ} \mathrm{C}$ for $2 \mathrm{~h}$ and the XRD patterns are shown in Fig. 3. The alumina peaks are identified as $\alpha$-alumina and zirconia peaks are identified as tetragonal zirconia in ZTA-2 as well. By using SC technique we could get $\alpha$-alumina because of the faster crystallisation due to the high temperature generated for a very short duration and also because of rapid cooling. The preparation of $\mathrm{Al}_{2} \mathrm{O}_{3}$ in $\alpha$-phase is beneficial to the consolidation process.

The average crystallite sizes of $\mathrm{ZrO}_{2}$ and $\mathrm{Al}_{2} \mathrm{O}_{3}$ calculated from Debye-Scherrer equation were 29 and $21 \mathrm{~nm}$ for ZTA-1 and 5 and $4 \mathrm{~nm}$ for ZTA-2. The stabilisation of the t-phase may be due to the small crystallite size as well as to the constraining effect of the matrix phase of the $\mathrm{Al}_{2} \mathrm{O}_{3}$. The SEM micrographs of ZTA exhibit flaky morphology (Fig. 4). The bright-field transmission electron micrographs of the nano/nano composite powders of ZTA-1 and ZTA-2 are shown in Fig. 5. The general features of the micrographs are described below. Alumina is seen as the bright phase and

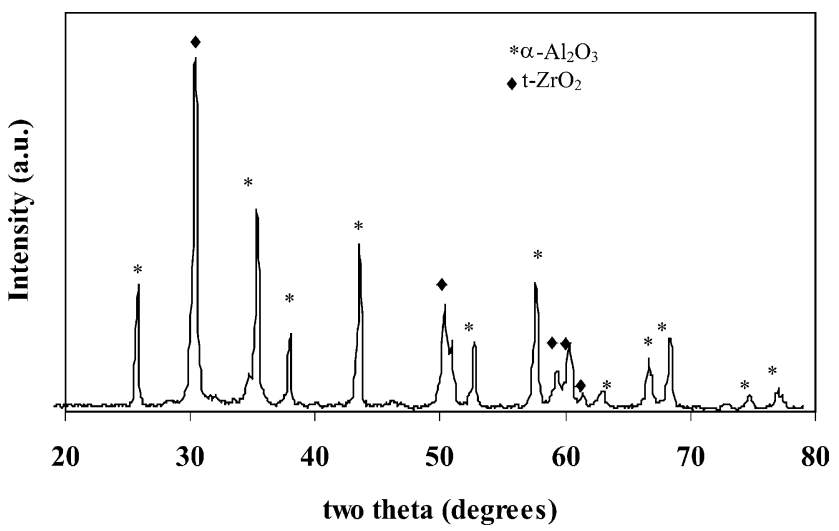

Fig. 2. Powder XRD pattern of ZTA-1. 


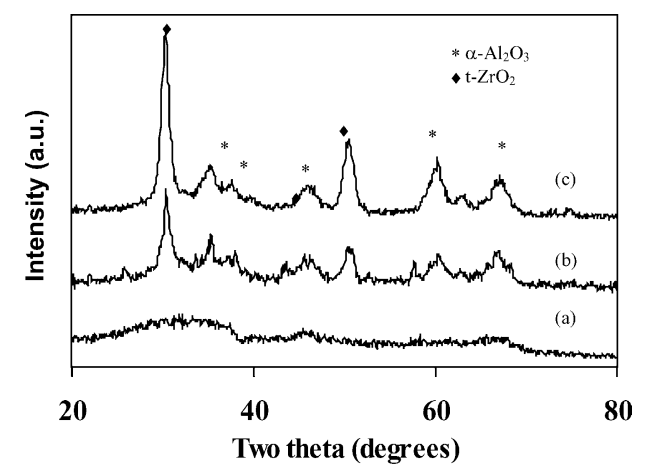

Fig. 3. Powder XRD patterns of ZTA-2: (a) as-formed, (b) calcined at $900{ }^{\circ} \mathrm{C}$, and (c) calcined at $1000{ }^{\circ} \mathrm{C}$.

zirconia as the dark phase in the TEM. The zirconia particles are uniformly and homogeneously distributed throughout the matrix as evident from the micrographs. As measured by transmission electron micrographs, the average particle size of $\mathrm{Al}_{2} \mathrm{O}_{3}$ was 40 and $9 \mathrm{~nm}$ and that of $\mathrm{ZrO}_{2}$ was 34 and $9 \mathrm{~nm}$ for ZTA-1 and ZTA-2, respectively. The particle size histograms for ZTA-1 and ZTA-2 obtained from TEM are shown in Figs. 6 and 7. They show fairly uniform particle size distribution. Thus, the $\mathrm{XRD}$ and TEM results substantiate the use of mixture of fuels concept in reducing the particle size to below $10 \mathrm{~nm}$ for ZTA. The particle size values calculated from TEM are slightly higher than that obtained from XRD data. The observed variation in the sizes calculated from XRD and TEM may be due to the formation of nanocomposites.

In the literature, the observed particle size differences of oxides prepared by solution combustion technique using various fuels is usually explained based on the differences in the number of moles of gases liberated during the reaction [18]. From the Eqs. (1) and (2), it is clear that the number of moles of gases liberated in both the reactions are almost identical ( $28 \mathrm{~mol}$ per mole of ZTA). But in the present study, the observed difference in the nature of combustion should be due to the use of ammonium acetate. In the literature, ammonium acetate is reported as a good fire extinguisher [19]. Thus, we assume that as the amount of ammonium acetate is increased, the flame which arises due to the urea fuel will be extinguished by ammonium acetate and the exothermicity decreases and hence the flame temperature decreases. This flame temperature is not enough for crystallisation of the particles and thus resulting in amorphous particles. A thorough investigation on the exact role of ammonium acetate is indispensable. The specific surface area of ZTA-1 and ZTA-2 are 2.6 and $7.7 \mathrm{~m}^{2} / \mathrm{g}$, respectively (Table 2). Approximately, a three-fold increase in the surface area was achieved by changing the fuel from urea to a mixture of fuels. The marked difference in the surface area is attributed to the choice of the fuel that alters the energetics of the combustion reaction and eventually the

Table 2

Properties of as prepared ZTA-1 and ZTA-2 powders

\begin{tabular}{|c|c|c|c|c|c|c|}
\hline \multirow[t]{2}{*}{ Sample } & \multirow{2}{*}{$\begin{array}{l}\text { Powder } \\
\text { density }\left(\mathrm{g} / \mathrm{cm}^{3}\right)\end{array}$} & \multirow{2}{*}{$\begin{array}{l}\text { Surface } \\
\text { area }\left(\mathrm{m}^{2} / \mathrm{g}\right)\end{array}$} & \multicolumn{2}{|c|}{ Particle size from XRD (nm) } & \multicolumn{2}{|c|}{ Particle size from TEM (nm) } \\
\hline & & & $\mathrm{Al}_{2} \mathrm{O}_{3}$ & $\mathrm{ZrO}_{2}$ & $\mathrm{Al}_{2} \mathrm{O}_{3}$ & $\mathrm{ZrO}_{2}$ \\
\hline ZTA-1 & 3.5 & 2.6 & 29 & 21 & 40 & 34 \\
\hline ZTA-2 & 2.1 & 7.3 & 5 & 4 & 9 & 9 \\
\hline
\end{tabular}




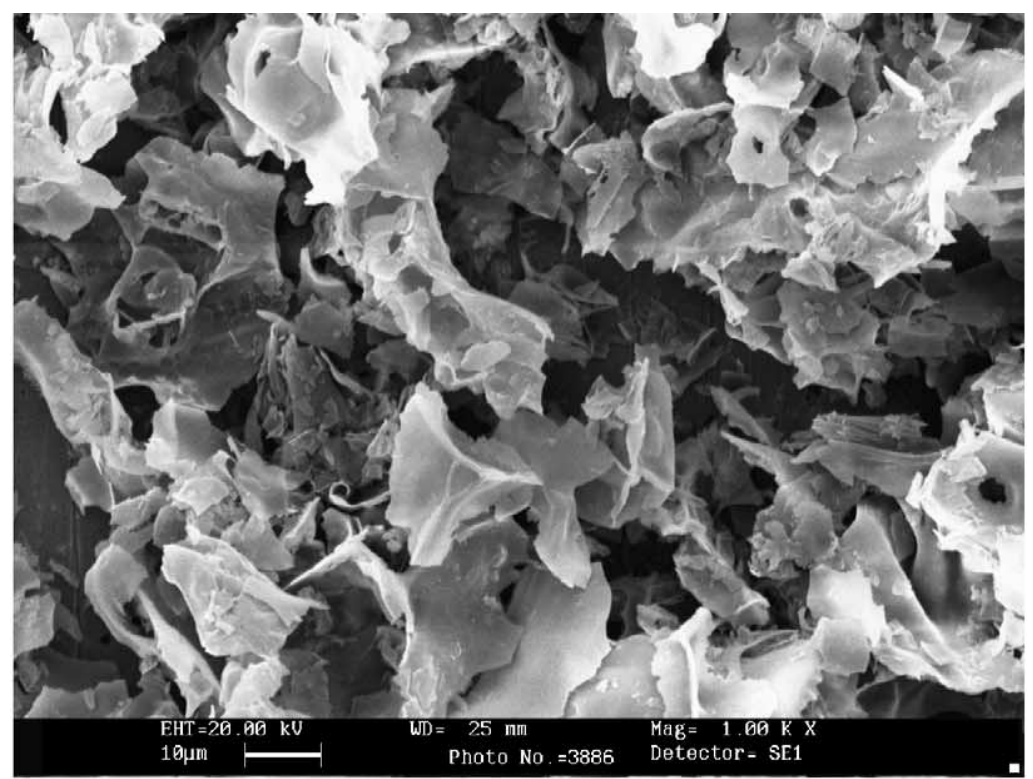

(a)

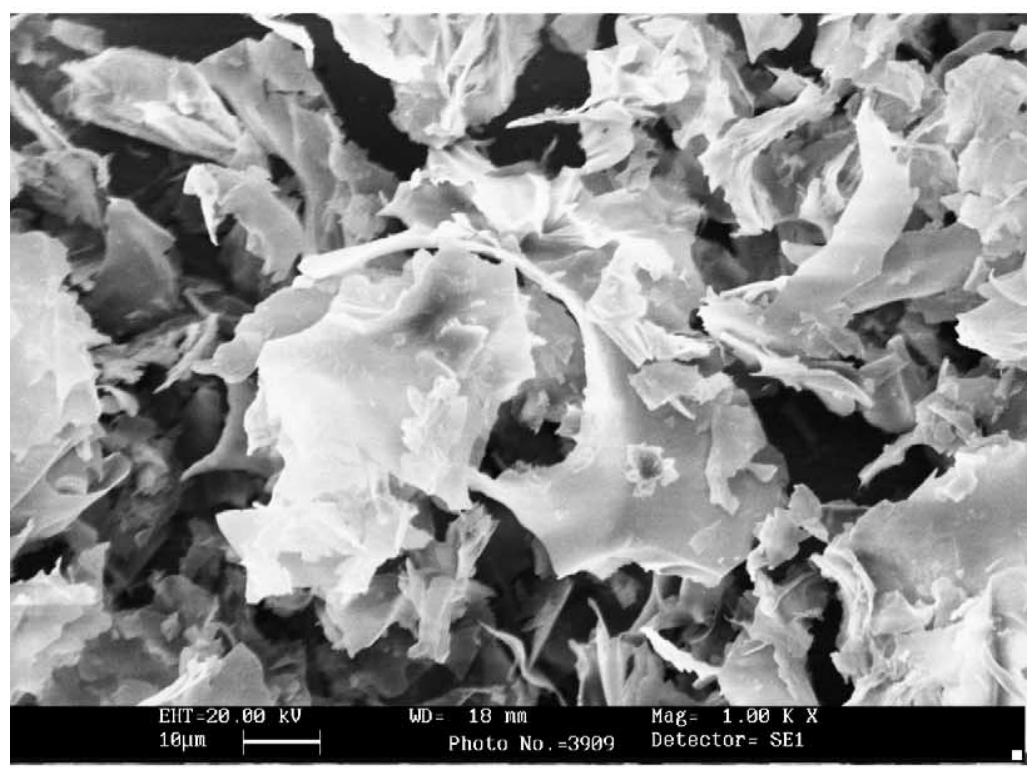

(b)

Fig. 4. Scanning electron micrographs of as prepared (a) ZTA-1 and (b) ZTA-2 foam.

properties of the combustion product. The nature and course of the decomposition products of the fuel and oxidiser appear to control the combustion behavior. The urea process yields oxides with low surface area, because of the formation of stable polymeric intermediates that prevent the dissipation of heat and thereby sintering the oxides during combustion [11]. The salient features of the use of mixture of fuels concept is (i) nanosize oxides $(<50 \mathrm{~nm})$ can be prepared at very low temperatures, (ii) the 


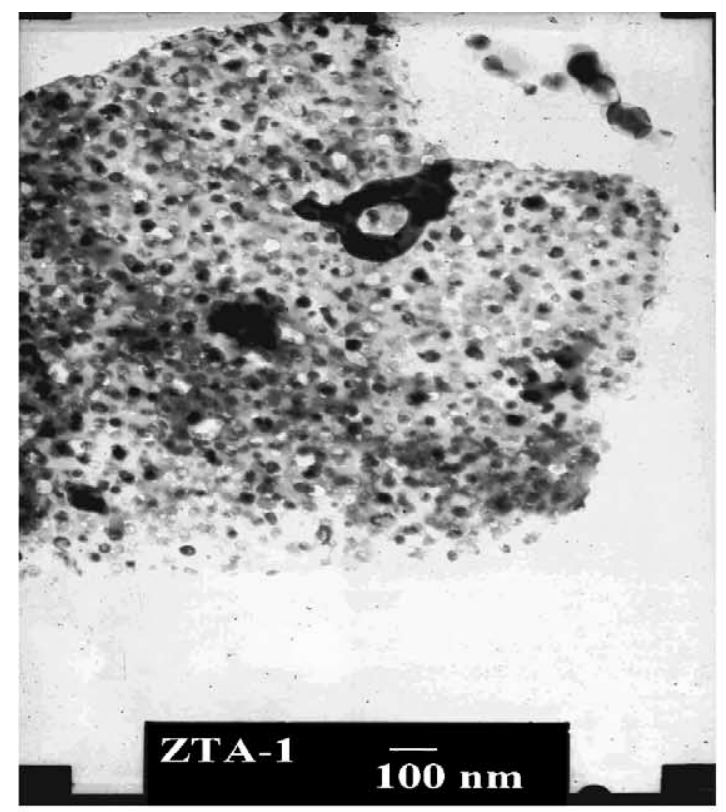

(a)

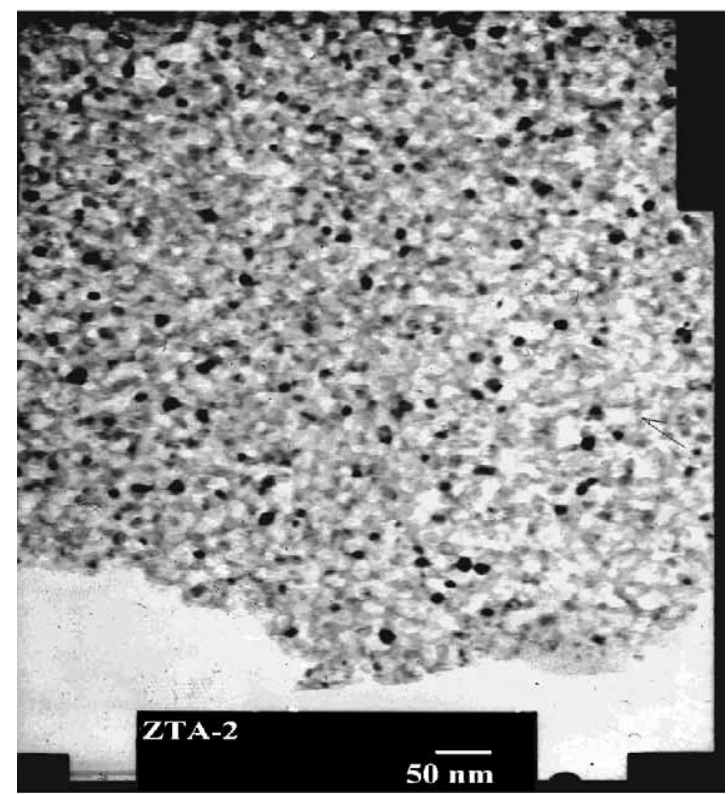

(b)

Fig. 5. Bright field transmission electron micrographs of (a) ZTA-1 and (b) ZTA-2 powders.

products are homogeneous and have high surface area, high purity, (iii) the particles show less agglomeration, and (iv) the fuels are readily available unlike the hydrazides which have to be prepared. The powders were heat-treated at $1200{ }^{\circ} \mathrm{C}$ with a soaking period of $5 \mathrm{~h}$. The nanocrystallinity of the microstructure was maintained even after high temperature treatment. The particle sizes for ZTA-1 after 

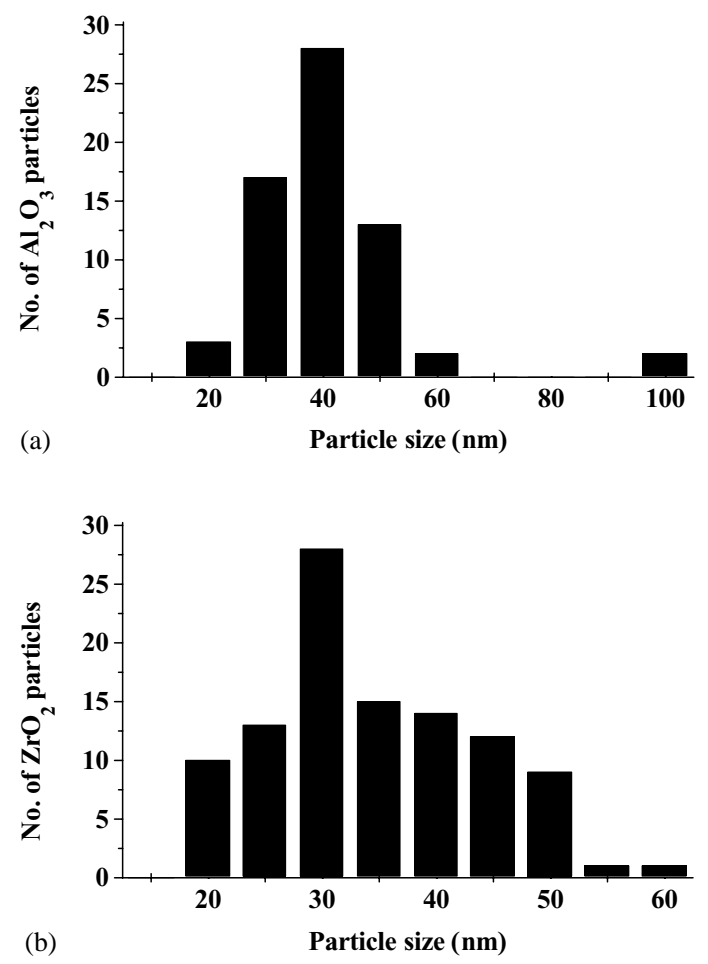

Fig. 6. Particle size histogram of ZTA-1 (a) $\mathrm{Al}_{2} \mathrm{O}_{3}$ particles (b) $\mathrm{ZrO}_{2}$ particles.

calcination at $1200{ }^{\circ} \mathrm{C}$ were 29 and $47 \mathrm{~nm}$ for $\mathrm{ZrO}_{2}$ and $\mathrm{Al}_{2} \mathrm{O}_{3}$ phases, respectively as calculated from XRD. Similarly for ZTA-2, the particle sizes after calcination at $1200{ }^{\circ} \mathrm{C}$ were 21 and $29 \mathrm{~nm}$ for $\mathrm{ZrO}_{2}$ and $\mathrm{Al}_{2} \mathrm{O}_{3}$ phases, respectively. Also, alumina and zirconia particles retain alpha and tetragonal phases, respectively. Usually the tetragonal zirconia undergoes transformation to monoclinic zirconia at $1200{ }^{\circ} \mathrm{C}$ [12]. But in case of ZTA-1 and ZTA-2, there was no phase transformation of tetragonal zirconia phase even after heat treatment at $1300{ }^{\circ} \mathrm{C}$. This indicates that the nanosize alumina particles prevent the tetragonal to monoclinic transformation by matrix constraint and keeps the zirconia particles apart to avoid the growth of $\mathrm{t}-\mathrm{ZrO}_{2}$. Also, even after sintering at $1300{ }^{\circ} \mathrm{C}$ the nanocrystalline nature was retained.

ZTA-1 and ZTA-2 powders were also sintered at $1400{ }^{\circ} \mathrm{C}$ for $5 \mathrm{~h}$ and the XRD patterns are as shown in Fig. 8. The particle sizes for ZTA-1 after calcination at $1400{ }^{\circ} \mathrm{C}$ were 50 and $83 \mathrm{~nm}$ for $\mathrm{ZrO}_{2}$ and $\mathrm{Al}_{2} \mathrm{O}_{3}$ phases, respectively as calculated from XRD. Similarly for ZTA-2, the particle sizes after calcination at $1400{ }^{\circ} \mathrm{C}$ were 30 and $72 \mathrm{~nm}$ for $\mathrm{ZrO}_{2}$ and $\mathrm{Al}_{2} \mathrm{O}_{3}$ phases, respectively. The transformation of tetragonal zirconia to monoclinic zirconia starts at $1400{ }^{\circ} \mathrm{C}$. The relative amounts of the t-phase and $\mathrm{m}$-phase in PSZ phase were estimated from the expression

$$
V_{\mathrm{m}}=\frac{\left(I_{\mathrm{m}}(11 \overline{1})+I_{\mathrm{m}}(111)\right)}{I_{\mathrm{m}}(11 \overline{1})+I_{\mathrm{m}}(111)+I_{\mathrm{t}}(111)} \times 100
$$

where $I$ is the intensity of the diffraction peak [20]. The percentage of monoclinic phase in case of ZTA-1 and ZTA-2 was 5 and $4 \%$, respectively after heat-treatment at $1400{ }^{\circ} \mathrm{C}$. Thus, it is evident that by decreasing the particle size of $\mathrm{t}-\mathrm{ZrO}_{2}$ one can also slow down the rate of transformation. 


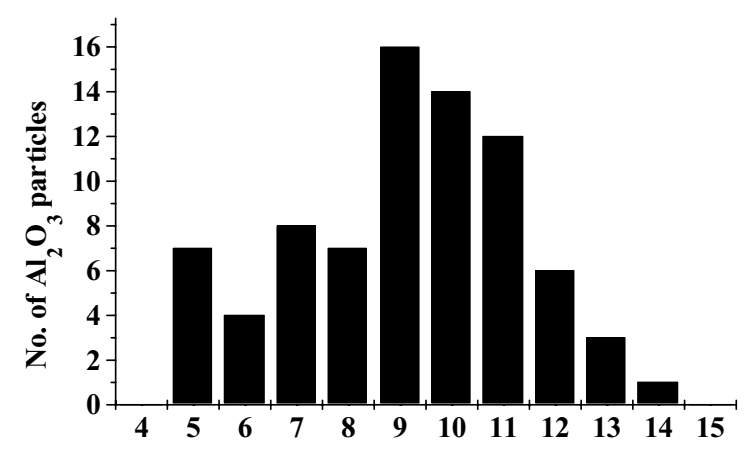

(a) Particle size (nm)

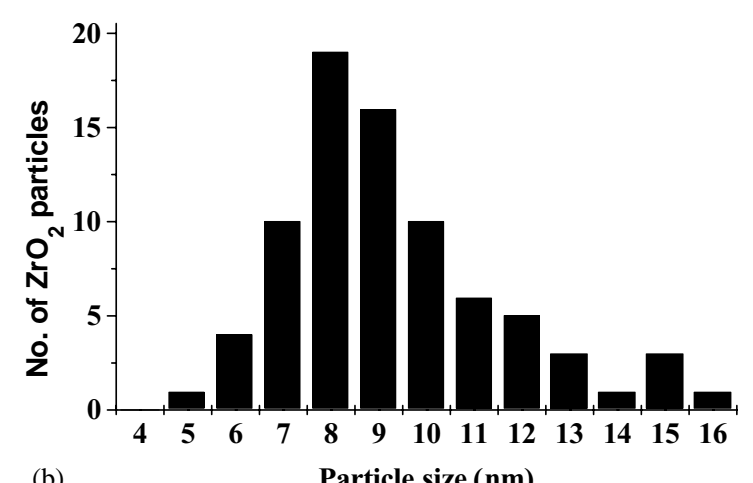

Fig. 7. Particle size histogram of ZTA-2 (a) $\mathrm{Al}_{2} \mathrm{O}_{3}$ particles (b) $\mathrm{ZrO}_{2}$ particles.

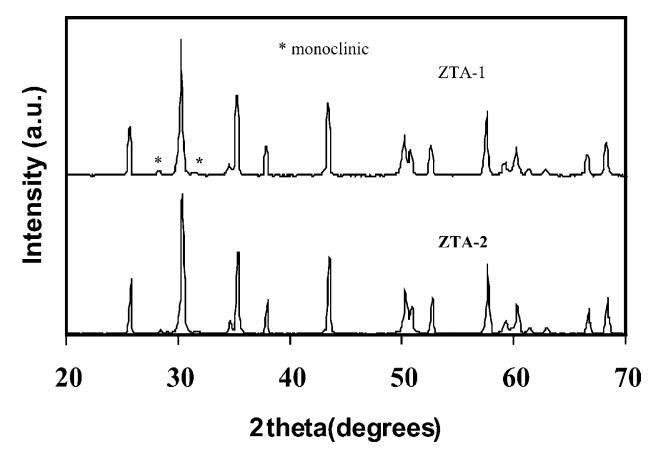

Fig. 8. Powder XRD patterns of ZTA-1 and ZTA-2 powders sintered at $1400{ }^{\circ} \mathrm{C}$.

\section{Conclusions}

The optimum concentration of urea and ammonium acetate required for preparing $\alpha-\mathrm{Al}_{2} \mathrm{O}_{3}$ with smaller crystallite size and lower agglomeration was fixed by carrying out a series of experiments. Mixture of fuels approach was used successfully for the preparation of $\mathrm{Al}_{2} \mathrm{O}_{3}-\mathrm{ZrO}_{2}$ nanocomposites. 
Both alumina and zirconia were nanocrystalline as revealed by TEM and XRD. In both the ZTA nanocomposites, alumina and $\mathrm{ZrO}_{2}$ exhibited the $\alpha$-phase and tetragonal phase, respectively. ZTA-1 prepared using urea alone as fuel had a particle size of $\sim 37 \mathrm{~nm}$ and surface area of $2.6 \mathrm{~m}^{2} / \mathrm{g}$. However, ZTA-2 prepared using mixture of fuels had a high surface area $\sim 7.7 \mathrm{~m}^{2} / \mathrm{g}$ and particle size of $\sim 9 \mathrm{~nm}$. Thus, it is concluded that by using mixture of fuels one can not only reduce the exothermicity of the combustion reaction but also reduce the particle size to a greater extent. Also, by using ammonium acetate along with urea, glycine and ammonium nitrate, the use of hydrazine based fuels is fully eliminated.

\section{Acknowledgements}

The authors are thankful to S. Tirosh, and Dr. Usha Devi, Mr. Venkataswamy, Kalavati and Roopa for the help rendered in TEM, XRD, SEM and particle size analysis studies, respectively. The authors thank the Director, NAL for giving permission to publish this work.

\section{References}

[1] G.H. Beall, L.R. Pinckney, J. Am. Ceram. Soc. 82 (1999) 5.

[2] H. Gleiter, Acta Mater. 48 (2000) 1.

[3] C. Suryanarayana, Bull. Mater. Sci. 17 (1994) 307.

[4] T. Sornakumar, M.V. Gopalakrishnan, R. Krishnamurthy, C.V. Gokularathnam, Int. J. Refrac. Met. Hard Mater. 13 (1995) 375.

[5] B. Mondal, A.B. Chattopadhyay, A. Virkar, A. Paul, Wear 156 (1992) 365.

[6] Y. Murase, E. Kato, K. Daimon, J. Am. Ceram. Soc. 69 (1986) 195.

[7] B. Kibbel, A.H. Heuer, J. Am. Ceram Soc. 69 (1986) 231.

[8] D.J. Green, J. Am. Ceram. Soc. 65 (1982) 610.

[9] B. Fegley Jr., P. White, H.K. Bowen, J. Am. Ceram. Soc. 68 (1985) C-60.

[10] M.L. Balmer, F.F. Lange, V. Jayram, C.G. Levi, J. Am. Ceram. Soc. 78 (1995) 1489.

[11] K.C. Patil, S.T. Aruna, S. Ekambaram, Curr. Opin. Solid State Mater. Sci. 2 (1997) 158.

[12] S. Bhaduri, S.B. Bhaduri, E. Zhou. J. Mater. Res. 13 (1998) 156.

[13] J.J. Kingsley, K.C. Patil, Mater. Lett. 6 (1988) 427.

[14] T. Mimani, K.C. Patil, Mater. Phys. Mech. 4 (2001) 134.

[15] S.R. Jain, K.C. Adiga, V.R. Pai Verneker, Combust. Flame 40 (1981) 71.

[16] J.J. Kingsley, K.C. Patil, Ceram. Trans. 12 (1990) 217.

[17] H.F. Mark, J.J. Mcketta Jr., D.F. Othmer, (Eds.), Kirk-Othmer Encyclopedia of Chemical Technology, vol. 2, Interscience, New York, 1967.

[18] S.T. Aruna, K.C. Patil, J. Mater. Synth. Process. 4 (1996) 175.

[19] Phoenix College Chemical Safety Procedures, Arnold Guerra, Phoenix College Press, 2002.

[20] R.C. Gravie, P.S. Nicholson, J. Am. Ceram. Soc. 55 (1972) 303. 